\title{
Contributions of Science and Technology to Better 品列品 Healthcare
}

\author{
Gundu H R Rao* \\ Emeritus Professor, Laboratory Medicine and Pathology, USA
}

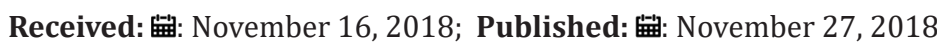

*Corresponding author: Gundu H R Rao, Emeritus Professor, Laboratory Medicine and Pathology, Director, Thrombosis Research, 12500 Park Potomac Ave Unit 306N, Potomac, MD 20854, USA

Abbreviations: NIH: National Institutes of Health; EHRs: Electronic Health Records; FOAD: Fetal Origin of Adult Diseases; CVD: Cardiovascular Disease; CNH: Children's National Hospital; AHA: American Heart Association; NPfiT: National Programme for Information Technology; CSC: Computer Services Corporation; GWAS: Genome-Wide Association Studies; SNP: Single Nucleotide Polymorphisms; AI: Artificial Intelligence

\section{Commentary}

Science and technology are the driving forces, in all fields of modern day living. Because, the innovations and applications of innovative ideas, transform every aspect of life process as we know, and from the point of view of this article, plays a major role in providing a better healthcare. Since the editorial team has invited me to write this special article, I Will take the liberty, to express my point of view on this subject. It is just one point of view, and everyone will have their own points of view, on such a fundamental issue. Since the title of my presentation is about healthcare, I will discuss few specific developments, not in any chronological order, to illustrate the complexities of everchanging developments in science and technology. Let me start with a major announcement, that the US President Barack Obama made in his State of the Union Address, on January 20, 2015. He announced, "Tonight, I am launching a new Precision Medicine Initiative, to bring us closer to curing disease like cancer and diabetes- and to give all of us access, to the personalized information we need to keep ourselves and our families healthier." The proposed initiative has two main components: a near-term focus on cancers and a longer-term aim, to generate knowledge applicable to the whole range of health and disease [1]. Anyone who heard this announcement, must have thought, that the cure for cancer and diabetes will be found soon.

According to Dr. Francis Collins, the Director, National Institutes of Health (NIH), USA, the researchers envisage assembling over time, a longitudinal "cohort" of 1 million or more Americans, who have volunteered to participate in research. Participants will be asked, to give consent for extensive characterization of biologic specimens (cell populations, proteins, metabolites, RNA, and DNA- including whole-genomes sequencing), and behavioral data, all linked to their electronic health records (EHRs). Cost of this ambitious project is over a Billion US Dollars. What better example one can have than this, for contributions of Science and Technology for better health care, or as the President puts it, for Precision Medicine or Personalized Medicine [1,2]. Now let us look at few examples of hypothesis driven research projects. Two major projects come to my mind. The first one, the now famous Framingham Heart Study, funded by the same prestigious NIH, which is celebrating 70 years of meticulous research, and the second one relating to Fetal Origin of Adult Diseases (FOAD), which also has completed over 70 years of research. The origins of the Framingham Heart Study are closely linked to the cardiovascular health of the US President, Franklin Roosevelt and his premature death, from the hypertensive heart disease and stroke in 1945.

The seminal studies from this research group, developed information about the modifiable risk factors, that promote the development of cardiovascular disease (CVD). Based on these and other clinical trials, diet-heart hypothesis was developed. Several major clinical trials have demonstrated the benefits of a healthy heart diet, and physical activity, in significantly reducing premature mortality [3-8]. It is believed, that dietary and physical activity recommendations, by various professional and regulatory bodies, have contributed significantly, to the observed decline in CVD mortality in the industrialized nations $[7,8]$. The second hypothesis was put forward by the British Epidemiologist, David Barker. According to him, intrauterine growth retardation, lowbirth weight, and premature birth, have a causal relationship to the 
origins of hypertension, coronary heart disease, and non-insulindependent diabetes, in middle age [9]. The basic epidemiological studies, that helped develop this hypothesis, were conducted at the Mission Hospital, Mysore, India, and at the UK. Studies on the new born children, are going on at the CSI Holdsworth Memorial Hospital in Mysore, India, since 1936.

In the early 1990s, small size at birth, was known to be associated with an increased risk for CVD, and some of its risk factors like hypertension, type- 2 diabetes, and dyslipidemia, in the UK, European, and the US populations. These associations were independent of adult lifestyle, and led to the Barker Hypothesis which proposed, that adult cardiometabolic disorders are "programmed" in utero, and result from persisting changes in metabolism and organ structure, that had occurred in response to fetal and early postnatal undernutrition [10]. In spite of this knowledge, even to this day in India, and some of the other Asian countries, more than $30 \%$ of the children born are of low birth weight and are "at risk" for developing metabolic diseases later in their adult life. In view of these observations, we have facilitated an international bilateral study, between the staff of Children's National Hospital (CNH), Washington DC, and the staff of Diabetes Clinic, KEM Hospital, Pune, India, to explore an alternate mechanism, which may modulate the programming of the fetal metabolism. This alternate hypothesis is based on the result of a study done at the CNH by Dr. Robert Freishtat and associates.

These researchers hypothesized, that adipocyte-derived exosome contain, mediators capable of activating end-organ inflammatory and fibrotic signaling pathways [11]. These bilateral studies are funded by the prestigious National Institutes of Health (NIH), USA. Now that we have discussed three major studies, looking at the origin of metabolic diseases, let us look at how the emerging technologies are making headway, to address these medical innovations and the need to accumulate, analyze, predict, and manage the information flow. If you look at the IBM Watson Health for instance, under the heading IBM Watson for Genomics, you see their claim: "Bringing the promise of precision medicine to more cancer patients, Watson can interpret genetic testing results faster, and with greater accuracy than manual efforts. Our partnership with Quest diagnostics means, that all providers can potentially benefit." In addition to the applications in Diagnostic and Therapeutic Oncology, the American Heart Association (AHA), IBM Watson, and Denver vendor Welltok, are teaming up on the creation of a workplace health solution, to improve heart health. In the first application of Watson to cardiovascular disease, AHA, IBM, and Welltok, will create a new offering that combines AHA's science-based metrics and health assessments, with cognitive analytics, delivered on Welltok's health optimization platform.

The effort is intended to help alleviate the burden of cardiovascular disease, which affect more than 85 million Americans today. Another one of a kind- effort to take advantage of the Big Data computing, is the effort of UK's National Health Services (NHS). The UK government chose the top-down, government approach: a "nationwide implementation of EHRs, known as the NHS Care Records Services, is the cornerstone of the 12.7 billion-pound
National Programme for Information Technology (NPfiT)." This very ambitious approach required enormous resources. "In order to begin the process of creating a system that supports health IT for the entire nation, the UK with the help of four companies including the US-based company, the Computer Services Corporation (CSC), began one of the largest and ambitious health IT projects, that the world had ever seen in early 2002. They hoped that the project will eliminate the challenges, of interoperability between various competitive ER systems around the UK." The one of a kind initiative came to an end in 2011 after spending huge sums of funds. In a short review like this, it will be hard to explain the many reasons behind the failure of this ambitious project.

We started this article, with the discussions on one of the most expensive and ambitious projects on precision medicine. The trouble with huge projects like this, without an underlying clear-cut hypothesis is, at times it will be hard to interpret or use the massive data generated in any meaningful way. Let me illustrate this with an example that is familiar. Researchers from Cardiff University, UK did a study on Platelet Lipidomes and reported the existence of over 5600 unique species of lipids, in resting platelets, with only $50 \%$ being putatively identified [12]. Thrombin-induced activation of platelets generated over 1500 sub species, and most predominantly upregulated lipids were, fatty acids and phospholipases. This information was known to the platelet lipid researchers half a century ago $[13,14]$. Furthermore, the thousands of lipids identified by the sophisticated LC/MS methodology, need explanation of their functional role in platelet physiology and function. Similarly, the Genome-wide association studies (GWAS) for instance, has resulted in the discovery of over 260 generic loci associated with obesity and type-2 diabetes [15].

GWAS studies are expensive, which is true of the genome sequencing studies suggested by Francs Collins as well, and the GWAS-derived single nucleotide polymorphisms (SNP), explain only a fraction of the heritability for complex traits. Having said this, experts feel the need to give genomic studies, a chance to prove their benefits are otherwise, in providing precision medicine capabilities. As we have seen in our discussions, meticulous planning and execution of scientific research does pay off, as evidenced by the success in preventing premature mortality, due to metabolic diseases. Many clinical studies have documented decline in CVD-related mortality in industrialized nations. Mysore cohort studies, which are as old as the Framingham studies, have documented the intrauterine risks for the developing child. Appropriate interventions will stop, reduce, reverse, or prevent fetal origin of adult metabolic diseases. Ambitious one of a kind studies mentioned above, such as the personalized genomic studies, or the IBM Watson and Artificial Intelligence (AI), are new and bold approaches.

As is with any new innovations, from discovery to application, takes several decades of meticulous work, financial support by the various stakeholders, and dedicated work by the team of investigators. Consider for instance, the success of biotechnology research during the last ten years. They have proved very useful in biomarker assays, molecular diagnostics, cellular and molecular 
therapies. If we look at science and technology, never these disciplines had so many potentials for application to public health and medicine.

\section{References}

1. Collins FS Varmus H (2015) A New Initiative on Precision Medicine. New Engl J Med 372: 793-795.

2. Collins FC, Gottileb S (2018) The next phase of Human Gene-Therapy Oversight. N Engl J Med 379: 1393-1395.

3. Mahmood SS, Levy D, Vasan RS, Wang TJ (2014) The Framingham Heart Study and the epidemiology of cardiovascular disease: a historical perspective. Lancet 383(9921): 999-1008.

4. Tsao CW Vasan RS (2015) Cohort profile: The Framingham Heart Study (FHS): overview of milestones in cardiovascular epidemiology. Int J Epidemiol 44(6): 1800-1913.

5. Gordon T, Kannel WB (1971) Premature mortality from coronary artery disease. The Framingham Study. JAMA 215(10): 1617-1625.

6. Pett KD, Kahn J, Willet WC, Katz DL (2017) Ancel Keys and the Seven Countries Study: Am evidence-based Response to Revisionist Histories. WHITE PAPER. The Truth Health Initiative.

7. Yusuf S, Hawken S, Ounpuu S, Dans T, Avezum A, et al. (2004) Effect of potentially modifiable risk factors associated with myocardial infarction in 52 countries (the INTERHEART study): case-control study. Lancet 364(9438): 937-952.

\section{ISSN: 2574-1241}

DOI: 10.26717/BJSTR.2018.11.002102

Gundu H R Rao. Biomed J Sci \& Tech Res

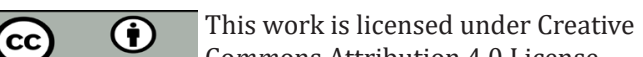

BY Commons Attribution 4.0 License

Submission Link: https://biomedres.us/submit-manuscript.php
8. Di Cisare M, Bennett JE, Best N, Stevens GA, Danaei G, et al. (2013) The contributions of risk factor trends to cardiometabolic mortality decline in 26 industrialized countries. Int J Epidemiol 42(3): 838-848.

9. Calkins K, Devaskar SU (2011) Fetal Origin of adult disease. Curr Probl Pediatr Adolesc Health Care 41(6): 158-176.

10. Krishna M, Kalyanaraman K, Veena SR, GV Krishanveni, SC Karat, et al. (2015) Cohort Profile: The 1934-66 Mysore birth records cohort in South India. Int J Epidemiol 44(6): 1833-1841.

11. Ferrante SC, Nadlre EP, Pillai DK, Hubal MJ, Wang Z, et al. (2015) Adipocyte-derived exosomal miRNAs: a novel mechanism for obesityrelated disease. Pediatr Res 77(3): 447-454.

12. Slatter DA, Sldrovandi M, O'Connor, Allen SM, Brasher CJ, et al. (2016) Mapping of the human platelet lipidome reveals cytosolic phospholipase $\mathrm{A} 2$ as a regulator of mitochondrial bioenergetics during activation. Cell Metab 23(5): 930-944.

13. Marcus A, Ulman HL, Safler LB, Ballard HS (1962) Platelet phosphatides. Their fatty acid and aldehyde composition and activity in different clotting systems. J Clin Invest 41(12): 2198-2212.

14. Marcus A, Spaet TH (1958) Platelet phosphatides: their separation, identification, and clotting activity. J Clin Invest 37(12): 1836-1847.

15. Meyre D (2017) Give GWAS a Chance. Diabetes 66(11): 2741-2742.

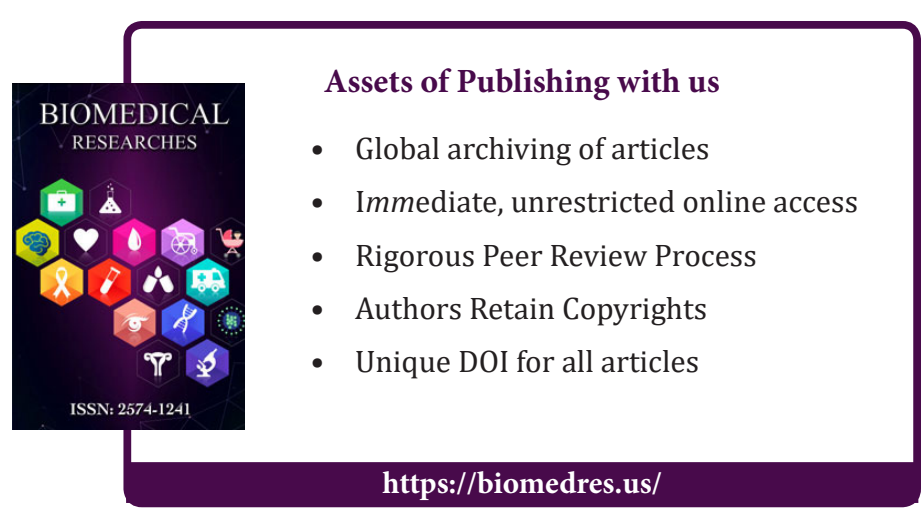

